\title{
In vitro Comparison of Safety and Efficacy of Diluted Isotonic Seawater and Electrodialyzed Seawater for Nasal Hygiene
}

This article was published in the following Dove Press journal: Medical Devices: Evidence and Research

\author{
Barbara De Servi $\mathbb{D}^{\prime}$ \\ Marisa Meloni (D) \\ Amina Saaid ${ }^{2}$ \\ Josip Culig ${ }^{3}$
}

'In Vitro Research Laboratories, VitroScreen SrL, Milan, Italy; ${ }^{2}$ Department of R\&D and Innovation, Laboratoire Fumouze, LevalloisPerret, France; ${ }^{3}$ Department of Pharmacology and Clinical Pharmacology, University of Applied Health Sciences,

Zagreb, Croatia
Correspondence: Barbara De Servi In Vitro Research Laboratories, VitroScreen Srl, Via Mosè Bianchi 103, Milan 20149, Italy Tel +39-02-89077608

Fax +39-02-454788I7

Email barbara.deservi@vitroscreen.com
Background: Nasal irrigation is often used for managing sinonasal conditions and maintaining nasal hygiene, which is critical to overall nasal health and to provide protection against airborne contaminants and pathogens. However, studies comparing efficacies of different solutions are needed.

Purpose: This in vitro study evaluated the ionic balance of an isotonic diluted seawater solution (Stérimar Nasal Hygiene, SNH) and its safety and efficacy for regular nasal hygiene in comparison to electrodialyzed seawater (EDS).

Materials and Methods: Ionic balance of SNH, EDS and pure seawater was measured by mass spectrometry and chromatography to be compared to the ionic balance of human plasma as reported in the literature. Safety was measured through cytotoxicity (lactate dehydrogenase release) and pro-inflammation (interleukin-8 secretion) assays using a 3Dreconstituted human nasal epithelium model. For efficacy, adenosine 5'-triphosphate (ATP) release assays, and histological (alcian blue) and immunohistochemical (aquaporin 3) stainings were performed on tissues under hypotonic challenge where saline solution was used as the negative control.

Results: Compared to EDS, the ionic balance of SNH was more similar to human plasma and pure seawater. SNH reduced hypotonic stress-associated ATP release and maintained tissue morphology more effectively and lastingly compared to EDS. Both solutions were safe to use on nasal epithelium, as neither of them caused cytotoxicity or induced (pro-) inflammation.

Conclusion: In comparison to EDS, this study confirms the safety and efficacy of SNH in maintaining good nasal hygiene consistent with its benefits reported in clinical trials.

Keywords: nasal irrigation, electrolyte balance, homeostasis, medical device, nasal mucosa

\section{Introduction}

Nasal irrigation, i.e. rinsing the nasal cavity with saline or seawater sprays/solutions, is often recommended to alleviate sinonasal symptoms. Several international associations endorse its use as an adjuvant treatment in conditions such as allergic rhinitis, common cold, rhinosinusitis or post-operative care after sinonasal surgery. $^{1,2}$ Additionally, nasal irrigation is recommended by the European Academy of Allergy and Clinical Immunology as an adjuvant to first-line therapies with antihistamines and topical steroids in acute and chronic rhinosinusitis. ${ }^{3,4}$ It has been recommended with its excellent safety profile as only minority of participants of the clinical trials evaluated in these position papers experienced minor nasal 
discomfort and/or irritation. It is also recommended by The French National Agency of Drug Safety for improving quality of life during common cold. ${ }^{5}$

Nasal irrigation allows a mechanical cleansing of the nasal cavity from mucus, crusts, cell debris, pollutants, and pathogens and helps prevent nasal infections. ${ }^{6}$ In general, nasal saline solutions are easy to use, well tolerated and improve nasal hygiene. ${ }^{7}$ The high tolerance and the efficacy of seawater in infants, children and adults suffering from seasonal or perennial allergic rhinitis or infection-related rhinitis have been demonstrated. Nasal irrigation with seawater can restore the nasal permeability after rhinitis episodes and could prevent the recurrence of cold and flu in children. ${ }^{8}$ Seawater irrigation acts by improving the elimination of secretions, moisturizing the nasal mucosa, facilitating drainage of the nasal cavity and thus enhancing nasal hygiene. In the pediatric population, saline nasal irrigation has been shown to be an effective method both for prevention and control of nasal congestion or obstruction. It is therefore recommended as an adjunct therapy for rhinosinusitis, allergic rhinitis and any other nasal congestion or mucosal obstruction cases. ${ }^{9}$

Seawater contains many minerals that are essential to life, such as sodium, bicarbonates, potassium, calcium and magnesium. In 1904, Rene Quinton showed that blood serum and interstitial fluid have an ionic balance practically identical to that of micro-filtered isotonic solution of ocean water $(0.9 \% \mathrm{w} / \mathrm{v} \mathrm{NaCl}) .{ }^{10}$ Based on this observation, he developed the concept of marine plasma (or diluted ocean water) which contains the full spectrum of minerals and trace elements found in human plasma. Recent evidence outlines the beneficial role of seawater over classic saline solutions for nasal irrigation. ${ }^{2,11,12}$ In this regard, studies comparing the efficacies of different seawater-based solutions are needed.

In this study, an in vitro reconstituted human nasal epithelium model (MucilAir ${ }^{\mathrm{TM}}$ ) has been used to assess the comparative safety and efficacy of isotonic diluted seawater to electrodialyzed seawater for nasal hygiene. First, the ionic balance of these solutions was compared to human plasma and pure seawater. Safety was evaluated via cytotoxicity (lactate dehydrogenase $[\mathrm{LDH}]$ release) and pro-inflammatory potential (interleukin 8 [IL-8] secretion) assays. The efficacy of these solutions on recovery from hypotonic stress conditions was evaluated by means of ATP release quantification and histochemical stainings (aquaporin 3 (AQP3) and alcian blue).

\section{Materials and Methods}

\section{Test Products}

Two different seawater-based nasal solutions were compared for their efficacy and safety. Stérimar Nasal Hygiene (SNH) Baby and Adults solution (Laboratoire Fumouze, Levallois-Perret, France) contains $31.82 \mathrm{~mL}$ seawater and purified water (qsp $100 \mathrm{~mL}$ ) and is sterilized by microfiltration. The second solution was Physiomer (Laboratoire de la Mer, Saint-Malo, France), a commercially available electrodialyzed seawater (EDS) sterilized by microfiltration in which $\mathrm{NaCl}$ in excess is removed through electrodialysis for an isotonic solution.

\section{Ion Concentration Determination}

One $\mathrm{mL}$ of solutions (SNH and EDS) was used to perform two measurements. Results for SNH and EDS are presented as a mean of analysis of three batches (six measurements in total), while one batch of pure seawater (not to confuse with saline solution as pure seawater contains elements other than sodium and chloride) was analyzed (two measurements). Concentrations of $\mathrm{Ag}, \mathrm{Ba}, \mathrm{Cd}, \mathrm{Co}$, $\mathrm{Cu}, \mathrm{Fe}, \mathrm{Mn}, \mathrm{Mo}, \mathrm{Ni}, \mathrm{Pb}, \mathrm{Se}, \mathrm{U}, \mathrm{V}$ and $\mathrm{Zn}$ ions were determined by inductively coupled plasma mass spectrometry (ICP-MS) according to the recommendations of ISO 17294-2. Iodine concentration was determined by ICP-MS according to the recommendations of ISO 15111. Concentrations of $\mathrm{B}, \mathrm{Ca}, \mathrm{K}, \mathrm{Mg}, \mathrm{Na}, \mathrm{S}, \mathrm{Si}$ and $\mathrm{Sr}$ were determined by ICP atomic emission spectrometry (ICPAES) according to the recommendations of the ISO 11885 standard. Chloride concentration was determined by ion-exchange chromatography (IC) according to the recommendations of ISO 10304.1.

\section{Biological Model Used for the in vitro Experimental Studies}

The remaining assays were performed in a $3 \mathrm{D}$ reconstituted human nasal epithelium model, MucilAir ${ }^{\mathrm{TM}}$ (Epithelix Sàrl, Geneva, Switzerland). Mucilair is a mixture of human nasal cells isolated from a panel of 14 different donors and has been selected for its great potential as a model to test respiratory sensitizers. ${ }^{13-16}$ Cells were cultured in $500 \mu \mathrm{L}$ of MucilAir ${ }^{\mathrm{TM}}$ culture medium in a $\mathrm{CO}_{2}$ incubator $\left(37^{\circ} \mathrm{C}, 5 \% \mathrm{CO}_{2}, 100 \%\right.$ humidity, Heracell, Waltham, Massachusetts, United States) in 24well plates with 6.5 -mm Transwell ${ }^{\circledR}$ inserts (Corning Life Sciences, Corning, New York, United States). Before treatments, inserts were washed with $200 \mu \mathrm{L}$ of MucilAir ${ }^{\mathrm{TM}}$ 
culture medium and the quality of the tissue was assessed under an inverted microscope (Carl Zeiss Axiovert 25, Oberkochen, Germany).

\section{Tissue Treatment}

For LDH and IL-8 assays (see details below), Mucilair ${ }^{\mathrm{TM}}$ tissues were treated with test and control solutions $(10 \mu \mathrm{L})$ twice a day with an 8-hour interval, for 4 days. Solutions were applied on the apical side of the epithelium in 24well plates. Each day (days 1, 2, 3 and 4), culture medium was frozen at $-80^{\circ} \mathrm{C}$ for further analysis. For ATP release quantification, AQP3 and alcian blue stainings (see details below), Mucilair ${ }^{\mathrm{TM}}-\mathrm{HF}$ tissues (Mucilair ${ }^{\mathrm{TM}}$ co-cultured with human airway fibroblasts) were treated with hypotonic solution $\left(300 \mu \mathrm{L}, 1 \mathrm{mM} \mathrm{CaCl}_{2}\right.$ and $1 \mathrm{mM} \mathrm{MgCl}_{2}$ solution) for 5 minutes, which was then immediately replaced with $100 \mu \mathrm{L}$ saline solution $(0.9 \% \mathrm{NaCl}$, control), SNH or EDS for 5 or 15 minutes. Tissues not subjected to hypotonic stress (ie treated with saline solution from the beginning of the assay) were used as negative control. For stainings, tissues were rinsed with saline solution and fixed in an adapted fixative. Samples were embedded in paraffin blocks and $5 \mu \mathrm{m}$ sections were obtained. The details of each experiment are described below:

\section{LDH Secretion}

LDH measurement was performed in untreated $(n=3)$, EDS-treated $(n=3)$, SNH-treated $(n=3)$ and $1 \%$ Triton $\mathrm{X}-100$ in saline solution-treated tissues (positive control, Fluka Biochemika, $\mathrm{n}=3$ ) by Cytotoxicity Detection KitPLUS (LDH, Roche, St. Louis, Missouri, United States) following manufacturer's instructions.

\section{IL-8 Secretion}

IL-8 secretion evaluation was performed by ELISA (BD OptEIA $^{\mathrm{TM}}$, BD Bioscience, Franklin Lakes, New Jersey, United States) in untreated $(n=3)$, EDS-treated $(n=3)$, SNH-treated $(\mathrm{n}=3)$ and Cytomix-treated (positive control, $\mathrm{n}=3$ ) tissues. Cytomix was composed of $1 \%$ FCS (Amimed, Cat 2-01F36-I, BioConcept Ltd, Allschwil, Switzerland), $0.2 \mathrm{mg} / \mathrm{mL}$ LPS (Sigma) and $500 \mathrm{ng} / \mathrm{mL}$ TNF- $\alpha$ (GeneTex, Irvine, California, United States).

\section{ATP Release Quantification}

Tissues were treated with saline, hypotonic solution and saline, hypotonic solution and EDS or hypotonic solution and SNH in triplicates. ATP was quantified by CellTiterGlo $^{\circledR}$ Luminescent Cell Viability Assay kit (Promega, Madison, Wisconsin, United States). Thirty microlitres of
CellTiter-Glo ${ }^{\circledR}$ reagent was added to $30 \mu \mathrm{L}$ of collected apical solution in three biological replicates. The plates were incubated at $37^{\circ} \mathrm{C}$ for 20 minutes and read in TECAN Infinite M200 (Tecan Group Ltd, Männedorf, Switzerland) (bioluminescence mode setting integration time of $1000 \mathrm{~ms}$ ). Two measurements per sample were performed.

\section{AQP3 Staining}

Tissues were treated with saline, hypotonic solution and saline, hypotonic solution and EDS or hypotonic solution and SNH in triplicates. Paraffin slides were deparaffinized, rehydrated, and incubated at $99^{\circ} \mathrm{C}$ for 8 minutes in citrate buffer for antigen retrieval. Tissues were then incubated overnight with primary rabbit polyclonal AQP3 antibody (1:500 in $1 \%$ BSA in PBS), 30 minutes with Histofine Simple Stain AP Multi (Nichirei Biosciences Inc, Tokyo, Japan), and with New Fuchsin chromogen (Nichirei Biosciences Inc, Tokyo, Japan) and examined under the Leica DM2500 microscope (Leica, Wetzlar, Germany) (40× magnification).

\section{Alcian Blue Staining}

Tissues were treated with saline, hypotonic solution and saline, hypotonic solution and EDS or hypotonic solution and SNH in triplicates. Slides were deparaffinized, rehydrated with distilled water and stained with alcian blue for 30 minutes. Counterstaining was performed with nuclear fast red solution for 5 minutes. Tissues were dehydrated in $95 \%$ and $100 \%$ alcohol, mounted with resinous mounting medium and analyzed under light microscopy (40× magnification).

\section{Results}

\section{lonic Balance of SNH Compared to EDS and Human Plasma}

In order to evaluate the ionic balance of solutions obtained by dilution and electrodialysis techniques, concentrations of ions were determined by IC, ICP-AES or ICP-MS (see methods for details). Samples included pure seawater $(\mathrm{n}=1)$, SNH $(\mathrm{n}=3)$ and EDS $(\mathrm{n}=3)$. Results were then compared to human blood plasma as per literature reports. ${ }^{17}$ As shown in Table 1, the ionic balance of SNH is clearly closer to both human plasma and pure seawater, compared to EDS, in which the total percentage of $\mathrm{Na}^{+}$and $\mathrm{Cl}^{-}$was significantly lower and the total percentage of $\mathrm{K}^{+}, \mathrm{Ca}^{2+}, \mathrm{Mg}^{2+}$ and $\mathrm{S}$ was significantly higher than human plasma, pure seawater and SNH. The ionic balance of SNH suggested that it is closer to human plasma than EDS. 
Table I lonic Balance of Stérimar Nasal Hygiene Compared to Other Solutions (Represented as \% of All Quantified 24 Elements)

\begin{tabular}{|c|c|c|c|c|}
\hline Electrolytes & $\begin{array}{l}\text { Pure Seawater from Cancale } \\
\text { Bay } \\
(\%, n=I)\end{array}$ & $\begin{array}{l}\text { Human } \\
\text { Plasma }^{17}\end{array}$ & $\begin{array}{l}\text { Stérimar Nasal } \\
\text { Hygiene } \\
(\%, n=3)\end{array}$ & $\begin{array}{l}\text { Electrodialyzed } \\
\text { Seawater } \\
(\%, n=3)\end{array}$ \\
\hline $\mathrm{Na}^{+}+\mathrm{Cl}^{-}$ & 91.10 & 86.50 & 89.50 & 68.00 \\
\hline $\mathrm{Na}^{+}$ & 31.80 & 40.70 & 49.90 & 30.90 \\
\hline $\mathrm{Cl}^{-}$ & 59.20 & 45.80 & 39.60 & 37.10 \\
\hline $\mathrm{K}^{+}+\mathrm{Ca}^{2+}+\mathrm{Mg}^{2+}+\mathrm{S}$ & 8.90 & 13.50 & 10.50 & 31.50 \\
\hline $\mathrm{K}^{+}$ & 1.14 & 2.10 & 1.30 & 0.50 \\
\hline $\mathrm{Ca}^{2+}$ & 1.15 & 1.23 & 1.40 & 3.50 \\
\hline $\mathrm{Mg}^{2+}$ & 3.80 & 0.30 & 4.50 & 16.80 \\
\hline S & 2.80 & 9.90 & 3.30 & 10.70 \\
\hline Others & $<0.1$ & $<0.1$ & $<0.1$ & 0.5 \\
\hline Total (\%) & 100.0 & 100.0 & 100.0 & 100.0 \\
\hline
\end{tabular}

\section{Safety Assessment} Lactate Dehydrogenase Secretion

As seen in Figure 1B and C, tissues treated with EDS and SNH had a similar LDH profile to untreated cells (Figure 1A), indicating that neither of these solutions are cytotoxic. Treatment with Triton X-100 was used as a positive control for cell lysis corresponding to $100 \%$ cytotoxicity (Figure 1D).

\section{Evaluation of Pro-Inflammatory Profile}

As observed in Figure 2, SNH and EDS treatments did not induce pro-inflammatory effects. In general, at all
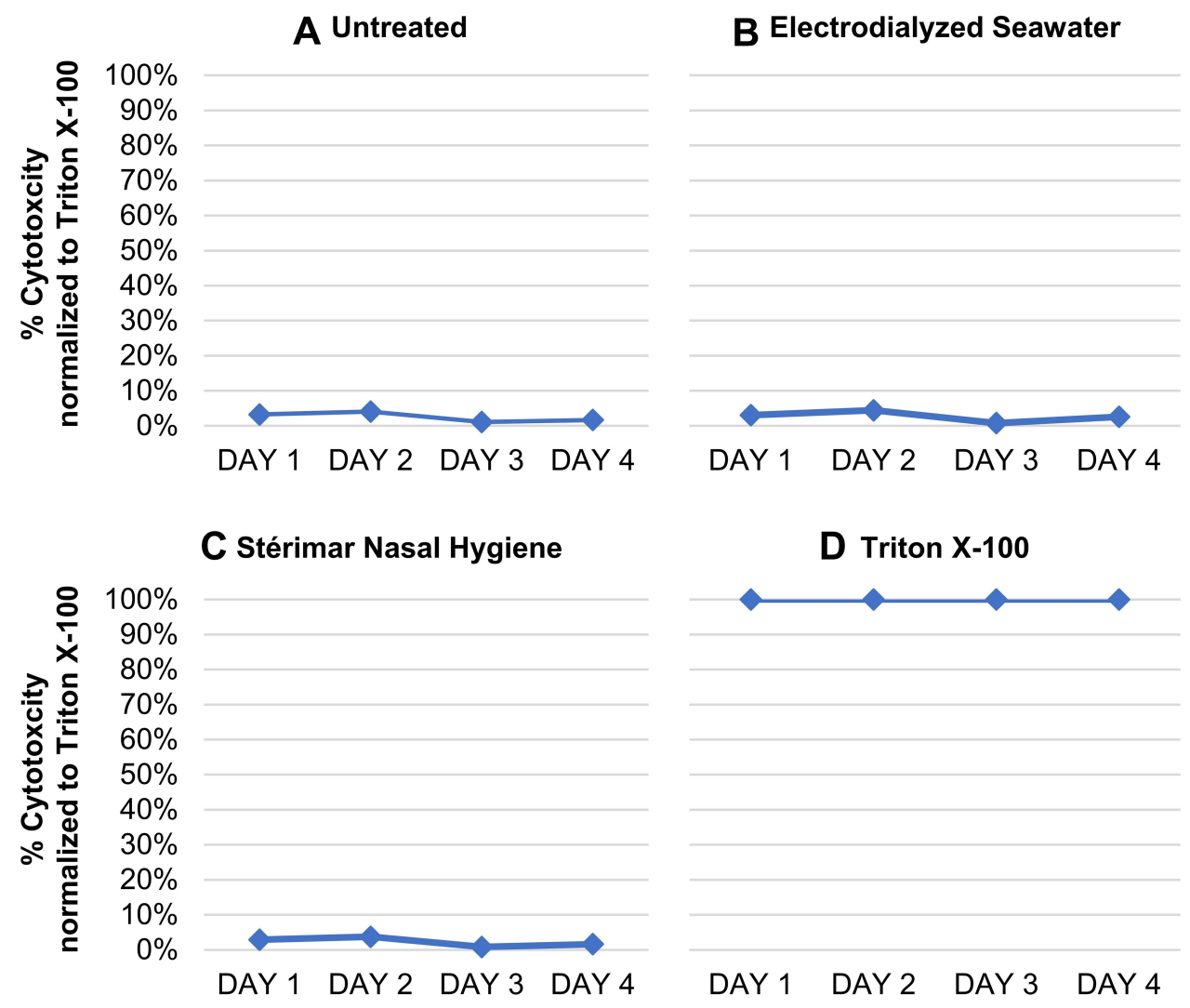

Figure I Effect of SNH and EDS on cytotoxicity. LDH secretion profiles in (A) untreated, (B) EDS-treated, (C) SNH-treated and (D) Triton X-I00-treated MucilAir ${ }^{\mathrm{TM}}$ tissues for 4 days. 


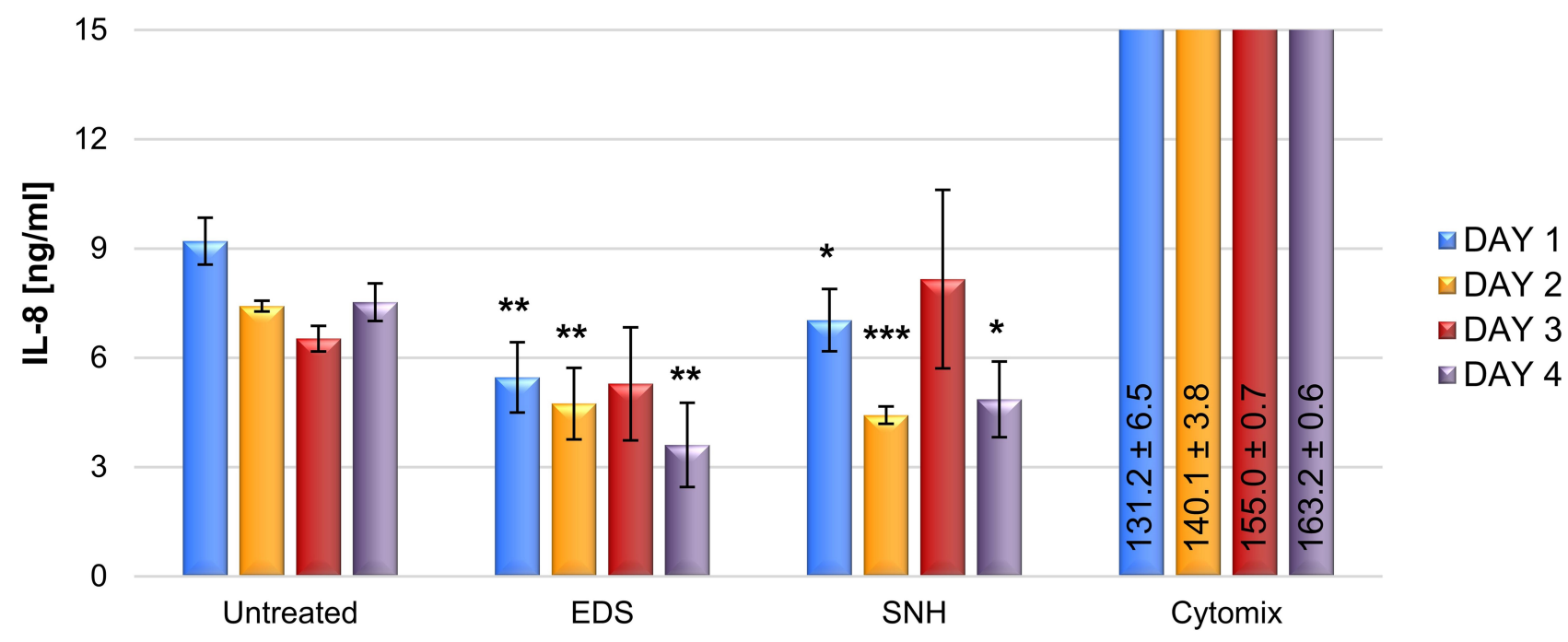

Figure 2 Effect of SNH and EDS on IL-8 secretion. Levels of IL-8 were measured by ELISA in untreated, EDS-treated, SNH-treated and Cytomix-treated MucilAir TM tissues for 4 days. ${ }^{*} p<0.05, * * p<0.01$ and $* * * p<0.001$ compared to untreated cultures. Error bars represent standard deviation. Abbreviation: IL-8, interleukin-8.

timepoints, there was a decrease in IL-8 levels compared to untreated cultures. Although there was an increase in IL-8 levels on Day 3 upon SNH treatment, this increase was not statistically significant compared to EDS-treated or -untreated samples, and on Day 4, there was a significant decrease in IL-8 levels compared to untreated cultures, confirming that SNH does not trigger any inflammatory process. Cytomix (see the Materials and Methods section) was used as a positive control, and, as expected, it induced a significant release of IL-8 at all timepoints.

\section{Effects on Tissue Morphology and Physiology ATP Release Quantification}

Figure 3A shows hypotonic stress-induced ATP release in all samples compared to the negative saline control
A

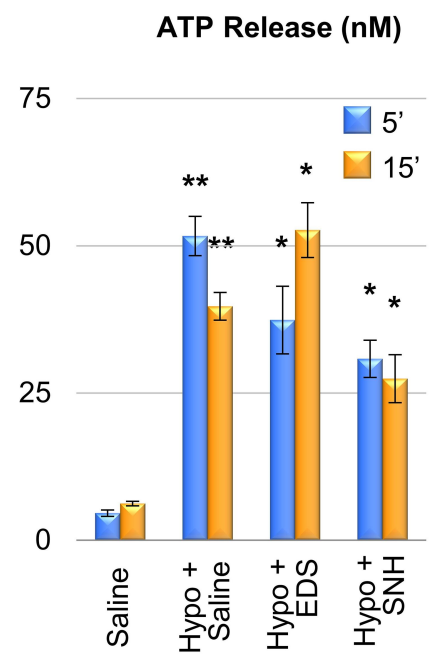

B

Alcian blue (Mucins in blue, cells in pink)
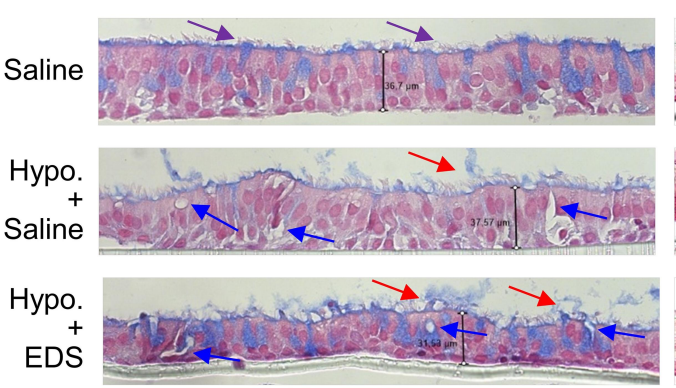

Hypo.

SNH

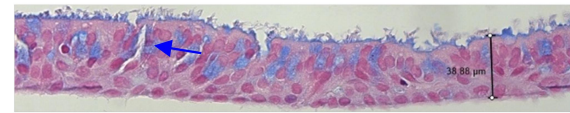

AQP3

(Pink)
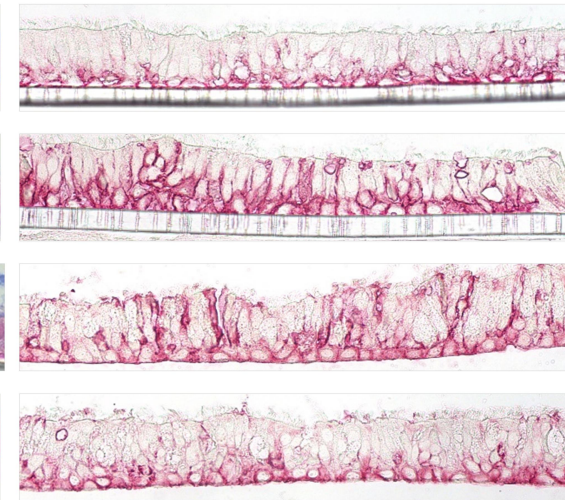

Figure 3 Evaluation of the ATP release and cell morphology effects of SNH compared to EDS. (A) ATP release in nM after 5 and I5 minutes of treatment following 5 minutes of hypotonic saline solution application. ${ }^{*} \mathrm{p}<0.05$, ${ }^{* *} \mathrm{p}<0.0 \mathrm{I}$, hypotonic solution was compared to saline-only control, EDS and SNH were compared to the hypotonic solution. (B) Histochemical staining of the treated tissues by alcian blue and AQP3 antibody, 15 minutes after treatment. Violet arrows: ciliated epithelial cells; blue arrows: protrusions or blebs; red arrows: damaged cilia. Error bars represent standard deviation.

Abbreviations: ATP, adenosine 5'-triphosphate; AQP3, aquaporin 3; hypo, hypotonic. 
$(p<0.01)$ at both time points. In tissues that were challenged with hypotonic solution, after 5 minutes of treatment with EDS or SNH, the levels of ATP were lower than in the sample treated with saline solution, indicating better recovery from the hypotonic stress $(\mathrm{p}<0.05)$. However, only the recovery due to $\mathrm{SNH}$ treatment was persistent after 15 minutes: ATP release levels in the SNH-treated sample are $30.9 \%$ less compared to the saline-treated sample $(27.43 \mathrm{nM}, \mathrm{p}<0.05)$ and $47.9 \%$ less compared to the EDS-treated sample. Surprisingly, at 15 minutes, a significant increase in ATP release is observed in the EDS-treated sample indicating a return to stress-like conditions as in saline-treated sample $(52.66 \mathrm{nM} \mathrm{p}<0.05)$. Thus, in reversing hypotonic stress, SNH has a more sustained effect than EDS compared to saline treatment.

\section{Alcian Blue and AQP3 Stainings}

The effect of stress on the morphology of the tissues was also monitored by alcian blue staining. As seen in Figure 3B (left panel), saline-only negative control tissues present a clear and regular organization of cuboidal mucusproducing goblet cells and ciliated epithelial cells (violet arrows). After hypotonic stress, initial cell swelling stimulated the exocytosis of numerous intracellular vesicles. By fusing with the plasma membrane, these vesicles cause the membrane to expand and form some protrusions (blue arrows). In tissues treated with saline solution for 15 minutes after hypotonic stress, cilia were damaged (red arrows) and less mucus was present on the surface. EDS treatment after hypotonic stress only partially restored cuboidal, mucus-producing goblet cells and ciliated epithelial cells. Holes, vacuoles and protrusions were still present. Differently, SNH treatment has better restored the morphology of the tissues, eliminating the majority of protrusions and blebs.

In homeostatic conditions, AQP3 is expressed mainly in the basal layer of the airway epithelium, ${ }^{18}$ as seen in isotonic saline solution-treated tissues (Figure 3B, right panel). Upon hypotonic stress and subsequent saline treatment, increase in the AQP3 expression was observed and the distribution of the staining was evident across the whole tissue, ie AQP3 expression is present not only in the basal layers but rather in the whole epithelium. EDS treatment did not restore normal AQP3 expression. However, SNH treatment re-established the pattern, localization and levels of AQP3 expression indicating a recovery in tissue morphology.

\section{Discussion}

Existing evidence has shown that nasal irrigation with saline or seawater solutions can help relieve nasal and sinus symptoms and is often recommended for nose hygiene and as an adjunct therapy. ${ }^{19,20}$ Evidence from clinical studies suggests that nasal washes with seawater solutions could restore the normal function of the nose after rhinitis episodes and help prevent recurrence of such episodes in both children and adults. ${ }^{8-21}$ In the present study, in vitro evidence on the safety and efficacy of $\mathrm{SNH}$, an isotonic seawater solution, has been presented in comparison to electrodialysed seawater.

First, the ionic balance of SNH and EDS was compared with that of human plasma and pure seawater (Table 1). The IC, ICP-MS and ICP-AES results showed that SNH has an almost identical ionic balance to human plasma, which is not the case for EDS. These results, confirmed by different assays, indicate that $\mathrm{SNH}$ is a safe and physiologically relevant agent for nasal irrigation.

The airway epithelium is the first line of defense in the upper respiratory tract and therefore its integrity is very important for the functionality of the respiratory system.

Since both solutions are designed for human use, the safety of these solutions was put to test through cytotoxicity and pro-inflammation assays on an in vitro nasal epithelial tissue.

Cytotoxicity was assessed by measuring extracellular LDH levels (Figure 1). LDH is released by dead cells and its measurement is a widely recognized method for assessing toxicity and cell membrane integrity. ${ }^{22}$ SNH or EDS treatments did not have a cytotoxic effect as assessed by LDH release quantification. Almost identical results were observed for untreated, EDS- and SNH-treated cultures, indicating that the cellular membrane remains intact upon treatment with both solutions.

On the other hand, pro-inflammatory markers were measured through ELISA-based IL-8 secretion assays (Figure 2). IL-8 is one of the most abundant proinflammatory mediators released by airway epithelial cells and elevated IL-8 levels indicate an inflammatory process. $^{23}$ The applications of SNH or EDS did not induce a pro-inflammatory response as shown by the evaluation of the IL-8 profile. Although there was an increase in IL-8 secretion on Day 3 of SNH treatment and compared to EDS-treated or -untreated samples, which was statistically insignificant, there was a significant decrease in its levels in comparison to untreated cultures on Day 4. Together 
with cytotoxicity data, this data indicates that both $\mathrm{SNH}$ and EDS are safe for human use.

Next, SNH was compared to EDS in recovery from hypotonic stress both via ATP release quantification and morphological evaluation through histological (alcian blue) and immunohistochemical (AQP3) stainings (Figure 3). Aquaporins are membrane water channel proteins that have a specific tissue distribution and cellular expression pattern and permit rapid and selective water transport across the membrane of the human airway epithelium in response to osmotic gradients. ${ }^{24,25}$ The ATP is a paracrine regulator of airway epithelia functions and is released in response to various mechanical stimuli including direct deformation of the cell membrane surface, physiological fluid shear stress and hypotonic stress-induced swelling. ${ }^{26-29}$ As a response to hypotonic stress conditions, cells swell via osmosis and exhibit increased ATP release. Isotonic solutions prevent excessive ATP efflux by sustaining the ionic equilibrium across the cell membrane. Post-hypotonic challenge, both SNH and EDS treatments induced a decrease of ATP after a 5-minute treatment. This positive effect was maintained for 15 minutes (last time point of the assay) in the case of SNH. On the contrary, an increase in ATP release was observed in EDS-treated tissues at this timepoint. These results are also supported by the morphological evaluation of the tissue: After hypotonic stress, cell swelling, exocytosis of numerous intracellular vesicles, membrane protrusions were observed. In tissues treated with saline solution for 15 minutes after hypotonic stress, cilia were damaged, and less mucus was present on the surface. However, SNH treatment allowed a more efficient recovery in cell morphology than EDS at the later timepoint (15 minutes). These data indicate that SNH preserves nasal epithelium homeostasis longer than EDS, and that dilution of seawater in SNH does not compromise efficacy, but rather maintains an ionic balance very close to that of human plasma. These in vitro results suggest that $\mathrm{SNH}$ would be more physiologically relevant for nasal irrigation than EDS.

\section{Conclusions}

In conclusion, the in vitro studies have shown that both EDS and SNH are safe for use on human epithelium. However, $\mathrm{SNH}$ is closer to human plasma than EDS in terms of ionic balance and superior to EDS in restoring sustained homeostasis after stress conditions. This in vitro research supports the clinical studies reported in the literature on safety and efficacy of seawater-water-based isotonic solutions in the maintenance of good nasal hygiene.

\section{Abbreviations}

3D, three dimensional; AQP3, aquaporin 3; ATP, adenosine 5'triphosphate; EDS, electrodialyzed seawater; ELISA, enzymelinked immunosorbent assay; FCS, fetal bovine serum; IC, ion-exchange chromatography; ICP-AES, inductively coupled plasma atomic emission spectrometry; ICP-MS, inductively coupled plasma mass spectrometry; IL-8, interleukin 8; LDH, lactate dehydrogenase; SNH, Stérimar Nasal Hygiene.

\section{Acknowledgments}

Authors would like to thank Dr Philippe Contencin, Dr Annahita Ghassemi and Noemie Durand for their valuable contribution to the elaboration and revision of the manuscript. The outcomes of this work have been partially presented as posters at the "12th International Conference on Allergy, Asthma \& Clinical Immunology" at Moscow (Russia), and at the "8th International Conference on Otorhinolaryngology" at Rome (Italy), both in October 2018.

\section{Author Contributions}

All authors made substantial contributions to conception and design, acquisition of data, or analysis and interpretation of data; took part in drafting the article or revising it critically for important intellectual content; agreed to submit to the current journal; gave final approval of the version to be published; and agree to be accountable for all aspects of the work.

\section{Funding}

This study has been sponsored by Church \& Dwight, Co., Inc.

\section{Disclosure}

AS formerly worked as the EU Technology \& Innovation Manager at Laboratoire Fumouze, who owns the Stérimar brand. AS has patents E3638257, EP2985027, and EP2985019 pending. The authors report no other conflicts of interest in this work.

\section{References}

1. Salib RJ, Talpallikar S, Uppal S, Nair SB. A prospective randomised single-blinded clinical trial comparing the efficacy and tolerability of the nasal douching products Sterimar and Sinus Rinse following functional endoscopic sinus surgery. Clin Otolaryngol. 2013;38:297-305. doi:10.1111/coa.12132

2. Bastier PL, Lechot A, Bordenave L, Durand M, de Gabory L. Nasal irrigation: from empiricism to evidence-based medicine. A review. Eur Ann Otorhinolaryngol Head Neck Dis. 2015;132:281-285. doi:10.1016/j.anorl.2015.08.001 
3. Fokkens W, Lund V, Bachert C, et al. EAACI position paper on rhinosinusitis and nasal polyps executive summary. Allergy. 2005;60:583-601. doi:10.1111/j.1398-9995.2005.00830.x

4. Fokkens WJ, Lund VJ, Mullol J, et al. European position paper on rhinosinusitis and nasal polyps 2020. Rhinology. 2020;58(Supplement 29):1-464. doi:10.4193/Rhin20.401

5. French National Agency for the Safety of Medicines and Health Products. Rappel sur le bon usage des médicaments vasoconstricteurs utilisés dans le rhume - Information pour les patients [Reminder on the proper use of vasoconstrictor drugs used in colds - Information for patients]. December 2017. Available from: https:/www.ansm. sante.fr/content/download/37587/494353/version/3/file/QR Vasoconstricteurs-Decongestionnants-Sphere-ORL_27-12-2017.pdf. Accessed June 2, 2020.

6. Rabago D, Zgierska A. Saline nasal irrigation for upper respiratory conditions. Am Fam Physician. 2009;80:1117-1119.

7. Elmiyeh B, Heywood RL, Prasad VMN, Chatrath P, Bassett P, Quiney R. A prospective, single-blind, randomised, crossover study comparing three nasal hygiene systems and corresponding patient preference for such devices. J Laryngol Otol. 2014;128:73-77. doi: $10.1017 /$ S0022215113003368

8. Slapak I, Skoupa J, Strnad P, Hornik P. Efficacy of isotonic nasal wash (seawater) in the treatment and prevention of rhinitis in children. Arch Otolaryngol Head Neck Surg. 2008;134:67-74.

9. Chirico G, Beccagutti F. Nasal obstruction in neonates and infants. Minerva Pediatr. 2010;62:499-505.

10. Quinton R. L'eau de mer, milieu organique [Seawater, organic medium]. Paris: Masson et Cie Editeurs; 1904.

11. Friedman M, Vidyasagar R, Joseph N. A randomized, prospective, double-blind study on the efficacy of dead sea salt nasal irrigations. Laryngoscope. 2006;116:878-882. doi:10.1097/01.mlg.0000216 798.10007.76

12. Cordray S, Harjo JB, Miner L. Comparison of intranasal hypertonic dead sea saline spray and intranasal aqueous triamcinolone spray in seasonal allergic rhinitis. Ear Nose Throat J. 2005;84:426-430. doi:10.1177/014556130508400713

13. Essaidi-Laziosi M, Brito F, Benaoudia S, et al. Propagation of respiratory viruses in human airway epithelia reveals persistent virus-specific signatures. $J$ Allergy Clin Immunol. 2018;141:2074-2084. doi:10.1016/j.jaci.2017.07.018

14. Sivars KB, Sivars U, Hornberg E, et al. A 3D human airway model enables prediction of respiratory toxicity of inhaled drugs in vitro. Toxicol Sci. 2018;162:301-308. doi:10.1093/toxsci/kfx255

15. Reus AA, Maas WJ, Jansen HT, et al. Feasibility of a 3D human airway epithelial model to study respiratory absorption. Toxicol in Vitro. 2014;28:258-264. doi:10.1016/j.tiv.2013.10.025
16. Upadhyay S, Palmberg L. Air-liquid interface: relevant in vitro models for investigating air pollutant-induced pulmonary toxicity. Toxicol Sci. 2018;164:21-30. doi:10.1093/toxsci/kfy053

17. Haynes WM. CRC Handbook of Chemistry and Physics. 91th ed. CRC press; 2010

18. Kreda SM, Gynn MC, Fenstermacher DA, Boucher RC, Gabriel SE. Expression and localization of epithelial aquaporins in the adult human lung. Am J Respir Cell Mol Biol. 2001;24:224-234. doi:10.1165/ajrcmb.24.3.4367

19. Kassel JC, King D, Spurling GK. Saline nasal irrigation for acute upper respiratory tract infections. Cochrane Database Syst Rev. 2010;3:CD006821.

20. Deckx L, De Sutter AI, Guo L, Mir NA, van Driel ML. Nasal decongestants in monotherapy for the common cold. Cochrane Database Syst Rev. 2016;10:CD009612.

21. Tano L, Tano K. A daily nasal spray with saline prevents symptoms of rhinitis. Acta Otolaryngol. 2004;124(9):1059-1062. doi:10.1080/ 00016480410017657

22. Cho MH, Niles A, Huang R, et al. A bioluminescent cytotoxicity assay for assessment of membrane integrity using a proteolytic biomarker. Toxicol in Vitro. 2008;22:1099-1106. doi:10.1016/j. tiv.2008.02.013

23. Cao HB, Wang A, Martin B, et al. Down-regulation of IL-8 expression in human airway epithelial cells through helper-dependent adenoviral-mediated RNA interference. Cell Res. 2005;15:111-119. doi:10.1038/sj.cr.7290275

24. Ablimit A, Aoki T, Matsuzaki T, et al. Immunolocalization of water channel aquaporins in the vomeronasal organ of the rat: expression of AQP4 in neuronal sensory cells. Chem Senses. 2008;33:481-488. doi:10.1093/chemse/bjn015

25. Nielsen S, King LS, Christensen BM, Agre P. Aquaporins in complex tissues. II. Subcellular distribution in respiratory and glandular tissues of rat. Am J Physiol. 1997;273:C1549-1561. doi:10.1152/ajpcell.1997.273.5.C1549

26. Button B, Picher M, Boucher RC. Differential effects of cyclic and constant stress on ATP release and mucociliary transport by human airway epithelia. $J$ Physiol. 2007;580:577-592. doi:10.1113/ jphysiol.2006.126086

27. Ohbuchi T, Takenaga F, Hohchi N, Wakasugi T, Ueta Y, Suzuki H. Possible contribution of pannexin-1 to ATP release in human upper airway epithelia. Physiol Rep. 2014;2:e00227. doi:10.1002/phy2.227

28. Okada SF, Nicholas RA, Kreda SM, Lazarowski ER, Boucher RC. Physiological regulation of ATP release at the apical surface of human airway epithelia. J Biol Chem. 2006;281:22992-23002. doi:10.1074/jbc.M603019200

29. Vidal LS Mechanisms of ATP release in airway epithelial cells [dissertation]. University of North Carolina at Chapel Hill; 2010
Medical Devices: Evidence and Research

\section{Publish your work in this journal}

Medical Devices: Evidence and Research is an international, peerreviewed, open access journal that focuses on the evidence, technology, research, and expert opinion supporting the use and application of medical devices in the diagnosis, monitoring, treatment and management of clinical conditions and physiological processes. The identification of novel devices and optimal use of existing devices which will lead to improved clinical outcomes and more effective patient management and safety is a key feature of the journal The manuscript management system is completely online and includes a very quick and fair peer-review system. Visit http:// www.dovepress.com/testimonials.php to read real quotes from published authors. 